\title{
SOCIAL DISCOUNTING UNDER UNCERTAINTY: A CROSS-COUNTRY COMPARISON
}

\author{
Cameron Hepburn $^{\dagger}$, Phoebe Koundouri ${ }^{\ddagger}$, \\ Ekaterini Panopoulou* And Theologos Pantelidis**
}

August 2006

Running title: Cross-country declining discount rates JEL Classification Numbers: Q48, C13, C53, E43.

Keywords: discounting, uncertainty, regime-switching models, climate change policy, nuclear power

† St Hugh's College, Environmental Change Institute and Department of Economics, Oxford University, United Kingdom.

Email for correspondence: cameron.hepburn@economics.ox.ac.uk

$\ddagger$ Department of International and European Economic Studies, Athens University of Economics and Business, Greece, Department of Economics, University of Reading, UK, and Department of Economics, University College London, UK.

* Department of Banking and Financial Management, University of Piraeus, Greece and Department of Economics, National University of Ireland Maynooth.

** Department of Banking and Financial Management, University of Piraeus, Greece. 


\title{
SOCIAL DISCOUNTING UNDER UNCERTAINTY: A CROSS-COUNTRY COMPARISON
}

\begin{abstract}
Recent research suggests that social cost-benefit analysis should be conducted with a declining discount rate. For instance, Newell and Pizer [23] show that the U.S. certainty-equivalent discount rate declines through time, using a simple autoregressive model of U.S. interest rates. This paper extends that line of research, estimating both autoregressive and regime-switching models of real interest rates to determine certaintyequivalent discount rates in Australia, Canada, Germany and the United Kingdom. It is found that the regime-switching model is a better model of past interest rate behavior for all four countries. This model tends to produce a more rapid decline in certainty-equivalent discount rates. The paper provides applications to the economics of climate change and nuclear power.
\end{abstract}

JEL Classification Numbers: C13, C53, E43, D61, H83.

Keywords: discounting, uncertainty, regime-switching models, climate change, nuclear power 


\section{Introduction}

Whenever economists think about intertemporal decisions, we reach almost instinctively for a discount rate. This instinct has proven to be eminently sensible, and discounting has served us extremely well in formulating policy over the short to medium term. However, for longer term decisions — climate change mitigation is the classic example — standard discounting produces results that are contrary to intergenerational equity, if not commonsense. Indeed, Schelling [31], Kopp and Portney [17] and Page [26], among others, have questioned whether conventional discounting is appropriate for such policy decisions.

Indeed, those like Weitzman [35] with the 'uneasy intuitive feeling that something is wrong, somewhere', have ultimately had their suspicions confirmed. Although uncertainty can be ignored over short time-horizons, over longer horizons uncertainty in future economic growth rates (and hence in future discount rates) becomes more and more important. Under such circumstances, intertemporal efficiency demands that a certainty-equivalent discount rate be employed, and it is now clear that this discount rate will often decline through time [8, 9, 35-37]. Incidentally, employing declining discount dates also places greater weight upon future impacts, reducing the apparent tension between intergenerational equity and efficiency. Moreover, declining utility discount rates may be necessary to achieve particular axioms of intergenerational equity and sustainability $[3,19,20]$. Interestingly, declining utility discount rates also reflect experimental and empirical evidence on human behavior $[7,22]$. As if this were not enough, declining utility discount rates can also result from aggregating heterogenous intertemporal preferences [10]. 
While each of these various rationales for the use of declining discount rates has a certain appeal, ${ }^{1}$ in this paper we focus exclusively on calculating efficient social discount rates under uncertainty, for two reasons. First, social cost benefit analysis (CBA) is designed to select efficient projects, leaving equity considerations to other mechanisms. Second, it is questionable whether the approaches based on intergenerational equity or evidence of individual behavior are suitable for public policy. For instance, where axioms of intergenerational equity are the starting point, the parameters underlying the schedule of declining discount rates cannot easily be observed and must be chosen arbitrarily. Similarly, it is questionable whether hyperbolic discounting, as a theory of individual discounting explaining seemingly 'irrational' behavior such as drug addiction, ought to be subscribed to as a model for social decision making. For these reasons, simply employing the efficient discount rates under uncertainty is more appropriate for government guidance. Indeed the UK government has recently altered its long-term project appraisal guidance to reflect future uncertainty [14].

A convenient proxy for the uncertainty in social discount rates is arguably the uncertainty in the risk-free interest rate on government bonds. ${ }^{2}$ In an important paper on discounting under uncertainty, Newell and Pizer [23] make effective use of this proxy. Employing a simple autoregressive model of US interest rates, they derive a working definition and estimation of the certainty-equivalent forward rate (CER)

\footnotetext{
${ }^{1}$ See Pearce et al. [28] and Groom et al. [11] for a detailed discussion of the rationales for using declining social discount rates.

${ }^{2}$ This is not to suggest that the appropriate social discount rate is the risk-free market interest rate. On the contrary, because of a variety of market failures, it is broadly agreed that the social discount rate should be based on the social rate of time preference, with an adjustment for the shadow price of capital [21].
} 
for use in CBA. Their analysis confirms that the CER is largely declining through time, and that the rate of decline is a function of the uncertainty and also the persistence in past interest rates. Recently, Groom et al. [12] have argued that such a simple autoregressive model is unlikely to be sufficiently versatile to reproduce the empirical regularities typically found in interest rate series. They emphasize the importance of model selection for both the estimation of the schedule of empirical discount rates appropriate for CBA in the United States.

In this paper, we build on the results of both Newell and Pizer [23] and Groom et al. [12] by investigating the importance of model selection in a cross-country analysis. More specifically, we estimate both an autoregressive model and a regimeswitching model for the real interest rates of Australia, Canada, Germany and the United Kingdom and compare the estimated discount rates. In all four countries (especially Canada and Germany), statistical inference supports a regime-switching model. We also find that the regime-switching model places a substantially higher weight on events in the distant future. The policy implications are examined in two case studies - the value of carbon mitigation and the appraisal of nuclear build. Accompanying this analysis is an examination of country heterogeneity in certainty-equivalent social discount rates.

The rest of the paper is organized as follows. In section 2 we define the CER and we also introduce the econometric models used in this study. The data, together with the estimation and simulation results are described in section 3 , while section 4 presents the two case studies. Finally, section 5 concludes this paper. 


\section{Discounting and Interest Rate Models}

Future cash flows in period $t$ can be converted to present-day equivalents using a discount factor $D_{t}$. This can also be expressed as a function of the relevant discount rates, according to $D_{t}=\exp \left(-\sum_{i=0}^{t} r_{i}\right)$, where $r_{i}$ is the prevailing discount rate for each discrete period, and continuous compounding is employed. ${ }^{3}$ When $r$ is stochastic, the expected discounted value of a dollar delivered after $t$ years is:

$$
\mathrm{E}\left(D_{t}\right)=\mathrm{E}\left(\exp \left(-\sum_{i=0}^{t} \tilde{r}_{i}\right)\right)
$$

In the language of Weitzman [35], equation (1) simply describes the certaintyequivalent discount factor. The corresponding certainty-equivalent forward rate for discounting between adjacent future periods $t$ and $t+1$ is given by:

$$
\widetilde{r_{t}}=\frac{\mathrm{E}\left(D_{t}\right)}{\mathrm{E}\left(D_{t+1}\right)}-1
$$

Our focus here is upon specifying an appropriate model that captures the stochastic nature of $\widetilde{r_{t}}$, based on the observed dynamics of past interest rates. If past interest rate behaviour provides an appropriate proxy for uncertainty in future discount rates, this will be of use in constructing appropriate discounting schedules for social cost benefit analysis. Our starting point is the relatively simple mean-reverting $A R(p)$ model employed by Newell and Pizer [23] for U.S. interest rates, specified as follows:

$$
r_{t}=\eta+e_{t}, \quad e_{t}=\sum_{i=1}^{p} a_{i} e_{t-i}+\xi_{t}
$$

where $\xi_{t} \sim N\left(0, \sigma_{\xi}^{2}\right), \eta \sim N\left(\bar{\eta}, \sigma_{\eta}^{2}\right)$ and $\sum_{i=1}^{p} a_{i}<1 .{ }^{4}$ However, modeling the long-

\footnotetext{
${ }^{3}$ The analogue for period-to-period compounding is $D_{t}=\sum_{i=0}^{t}\left(1+r_{i}\right)^{-1}$.

${ }^{4}$ Newell and Pizer [23] also consider a random walk model, i.e. an $A R(p)$ model with $\sum_{i=1}^{p} a_{i}=1$.
} 
run interest rate using constant coefficient models is likely to be unrealistic, since a number of factors - the economic cycle, oil crises, stock market crises, productivity and technology shocks - may account for time-varying behavior in the data generation process of the interest rate. In this respect, we introduce a model that is time-heterogeneous in the sense that it accounts for the possibility of time-varying parameters. Our regime-switching model has two regimes as follows:

$$
r_{t}=\eta_{k}+e_{t}, \quad e_{t}=\sum_{i=1}^{p} a_{i}^{k} e_{t-i}+\xi_{t}
$$

where $\xi_{t} \sim \operatorname{IIDN}\left(0, \sigma_{k}^{2}\right), k=1,2$ for the first and second regime respectively. Each regime incorporates a different speed of mean-reversion, along with a different permanent component, $\eta_{k}$, and error variance, $\sigma_{k}^{2}$. The probability of being in each regime at time $t$ is specified as a Markov 1 process, i.e. it depends only on the regime at time $t-1$, with the matrix of the transition probabilities ${ }^{5}$ assumed to be constant. ${ }^{6}$

We do not examine this model here as data for the countries at hand clearly reject the hypothesis of a unit root, see Section 3.1 for details.

${ }^{5}$ Let $R_{t}$ denote the regime at time $t$, and let $P$ and $Q$ denote transition probabilities, so that the matrix of probabilities is as follows:

$$
\begin{array}{cl}
\operatorname{Pr}\left(R_{t}=1 \mid R_{t-1}=1\right)=P, & \operatorname{Pr}\left(R_{t}=2 \mid R_{t-1}=2\right)=Q \\
\operatorname{Pr}\left(R_{t}=2 \mid R_{t-1}=1\right)=1-P, & \operatorname{Pr}\left(R_{t}=1 \mid R_{t-1}=2\right)=1-Q
\end{array}
$$

${ }^{6}$ Other interest rate models are also possible. For instance, Groom et al. [12] suggest a statespace model for U.S. data. Our cross country comparison is informative here - our analysis of a state-space model indicated that the relevant algorithm does not converge for three of the four countries, indicating that the dynamic path of discount rates in these countries is not highly non-linear, as the model would imply. 


\section{Empirical Results}

\subsection{Data and Estimation Results}

We investigate the behavior of the interest rates of Australia, Canada, Germany and the United Kingdom. ${ }^{7}$ For Australia, the nominal interest rate employed is from Commonwealth 10-year bonds, covering the period 1856 to 2004. For Canada, we consider the Government bonds $10+$ maturity rate for the period 1844 to 2004, while for Germany we use the 'All government securities' rate for the period 1804 to 2004. Finally, the nominal interest rate used for the U.K. is the 'United Kingdom $21 / 2 \%$ Consol Yield' rate for the period 1802 to $2004 .^{8}$ Our choice of interest rate is limited by the availability of data as well as our desire for the longest time series available. For all four countries, the inflation is calculated by the annual change in the Consumer Price Index. Based on the nominal rates, we calculate real rates by subtracting the 10 -year moving average inflation rate, so as to smooth shortterm price fluctuations. However, even this technique leads to negative real rates for specific years due to mainly extreme events, such as oil crises or wars. In order to make our model invariant to these economic crises, which affect interest rates temporarily, we estimated the crisis-induced level of inflation by including a dummy in a small model for the inflation rate. The estimated extra-level of inflation is then subtracted from the inflation in the periods of crises and our series of positive real rates is obtained. We then convert these rates to their continuously compounded equivalents. To smooth very short-term fluctuations, a 3-year moving average of the real interest rate series is employed and in order to avoid negative interest rates, we

\footnotetext{
${ }^{7}$ These countries were examined because they all have reliable long-run data on interest rates.

${ }^{8}$ Data provided by the Global Financial Data, Inc, available at http://www.globalfindata.com.
} 
use the natural logarithms of the series.

Table 1 presents the descriptive statistics of the series. Average interest rates range from $2.96 \%$ to $3.70 \%$ for Canada and Germany respectively. ${ }^{9}$ The standard deviations indicate that Canadian interest rates are the most volatile, with Australian rates the least volatile. The results of a variety of unit root tests, which are also reported in Table 1, confirmed that all four real interest rates are stationary. Consequently, we proceed by estimating a mean-reverting autoregressive model for each of the countries under examination. The relevant estimates are provided in Table 2. Lag selection was based on the Akaike Information criterion and typical misspecification testing for any remaining serial correlation in the residuals. ${ }^{10}$ Our estimates reveal that the real interest rates under scrutiny display various degrees of reversion to their implied unconditional mean. The German (Canadian) interest rate series is the most (least) persistent, reflected by autoregressive coefficients summing to 0.94 (0.79). The Canadian series is represented by the most parsimonious model — an $\mathrm{AR}(1)$ model is sufficient — while the Australian interest rate requires an $\mathrm{AR}(5)$ model.

Although they are simple, autoregressive models are highly unlikely to provide a realistic representation of the behavior of real interest rates over a long period, as explained in detail by Groom et al. [12]. We therefore also estimate a regimeswitching (RS) model, with results reported in Table 3. We assume the existence of two regimes: a low-volatility regime (regime-1) corresponding to periods of economic stability, and a high-volatility regime (regime-2) corresponding to periods of

\footnotetext{
${ }^{9}$ Table 1 reports values after a logarithmic transformation — the mean interest rates above correspond to the untransformed series: $2.96=e^{1.084}$ and $3.70=e^{1.310}$.

${ }^{10}$ These tests are not reported for brevity, but are available from the authors upon request.
} 
economic crises. For all four countries, regime-1 has a higher mean than regime-2, suggesting that real interest rates are usually higher in tranquil economic periods compared to periods of economic instability, probably due to expectations of increased future growth and low uncertainty over the future state of the economy. The estimated persistence suggests that tranquil periods show a lower degree of mean reversion. Finally, the estimated transition probabilities ( $P$ and $Q$ in Table 3) indicate that both regimes are highly persistent. For instance, the low volatility regime in Canada lasts 37 years, while the respective figure for the high volatility regime is 9 years.

\subsection{Model Selection}

Before proceeding to the estimation of the CERs, we evaluate the autoregressive and the regime-switching models using three statistical tests to determine whether a regime-switching model provides a more appropriate description of interest rates than a simple autoregressive model.

First, we examine the Regime Classification Measure (RCM) proposed by Ang and Bekaert [1]. The RCM is based on the view that a good regime-switching model should classify regimes sharply. A regime-switching model is good when, for each regime $k$, the smoothed ex-post probability $p_{k, t}=\operatorname{Pr}\left(R_{t}=k \mid \Omega_{t}\right)$ where $\Omega_{t}$ is the information set available at time $t$, is close to either zero or one. In our two-regime models, the RCM is calculated as follows

$$
R C M=400 * \frac{1}{T} \sum_{t=1}^{T} p_{t}\left(1-p_{t}\right)
$$

where $\mathrm{T}$ is the sample size. By construction the value of RCM ranges from 0 to 
100. An RCM close to zero indicates the existence of two distinguishable regimes, justifying the utilization of a regime-switching model. The RCM estimates for our regime-switching models are provided in Panel A of Table 4. In the cases of Canada and Germany, the RCM strongly supports the regime-switching model. On the other hand, results for Australia and the UK are borderline since the RCM value is close to 50 .

Second, as the RCM is not a formal test of whether a regime-switching model is preferable to a simple autoregressive model, we also apply the Likelihood Ratio $(L R)$ test. The estimated values of $L R$ for the four countries are given in Panel B of Table 4. Unfortunately, we cannot use the $X^{2}$ distribution to determine the significance of $L R$ due to the presence of nuisance parameters in its distribution. In order to overcome this problem, we estimate the empirical distribution of $L R$ based on Monte Carlo simulations. Specifically, for each of the four countries under examination we first generate 2000 series of length $\mathrm{T}$ based on the estimated autoregressive model. For each generated sample, we estimate both an AR model and an RS model, with $L R^{*}$ calculated as follows: $L R^{*}=-2 *\left(\log l_{A R}^{*}-\log l_{R S}^{*}\right)$ where $\log l_{A R}^{*}$ and $\log l_{R S}^{*}$ are the values of the log-likelihood function of AR and RS, respectively based on the simulated series. Finally, we calculate the significance of $L R$ based on the 2000 values of $L R^{*}$. The results, reported in the last line of Table 4 , support the utilization of a regime-switching model in all four cases. Similarly to RCM, results are most robust for Canada and Germany (p-values are 0.006 and 0.029 respectively).

Third, we test the relative forecasting accuracy of AR and RS based on an in-sample forecasting exercise. For each of the countries, the second half of the available sample is used in the forecasting exercise. The performance of $\mathrm{AR}$ and $\mathrm{RS}$ is evaluated 
based on the Mean Square Forecast Error (MSFE) criterion. The calculated MSFEs, reported in Table 5, indicate that a regime-switching model is to be preferred in all four cases. Interestingly, the superiority of RS over AR is more pronounced in the case of the UK where the MSFE of RS is by 8.63 percent lower than that of AR. In the rest of the cases, the MSFE of RS is by less than 2 percent lower than that of AR. ${ }^{11}$

In summary, the results presented in this subsection indicate that a regime-switching model is preferable to a simple autoregressive model in all four countries, especially for Canada and Germany. In the next subsection, we estimate the CERs based on a simulation methodology proposed by Newell and Pizer [23].

\subsection{Simulation Results}

Based on the estimates presented in Tables 2 and 3, we simulate 100,000 possible future discount rate paths for each model starting in 2005 and extending 400 years into the future. ${ }^{12}$ Initial values for lags of the real interest rate necessary for the simulation are set at 3.5\%, the rate used for CBA by HM Treasury [14]. This sharpens the focus on the decline in the discount rate, which avoids confusion with the fact that countries also have different levels of the applicable mean interest rate. The expected discount factors and CERs are calculated from equations (1) and (2) and are reported in Tables 6-7 and 8-9 for the autoregressive and regime-switching models respectively.

\footnotetext{
${ }^{11}$ The small differences between the MSFEs of RS and AR are not surprising, since in an insample forecast exercise we expect both models to perform well.

${ }^{12}$ The process of selecting parameters and shocks is available from the authors upon request.
} 
As expected, the two alternative models (autoregressive and regime-switching) generate significantly different results. In general, the regime-switching model produces higher discount factors than the autoregressive model, especially for the distant future. Naturally, the corresponding certainty-equivalent discount rates reveal the opposite picture - estimated CERs are smaller for the autoregressive model than the regime-switching model.

Additionally, the results indicate substantial differences between the four countries, which become more pronounced as the time horizon lengthens. After removing the level effect (discussed above), Canada has the higher discount factors for an horizon of 100 years or more. At the end of the forecast horizon, for the RS model the discount factor of Canada is 11, 5 and 4 times larger than that of the UK, Germany and Australia respectively. In short, if past interest rate uncertainty provides a guide to future uncertainty, social decision-making in all four countries should place more weight on events in the distant future.

\section{Policy Implications}

Several policy implications emerge from the differences among countries (and models) in CER estimates. We examine two. First, we follow Newell and Pizer [23] and Groom et al. [11] and consider the present value of carbon mitigation: the removal of one tonne of carbon from the atmosphere. Secondly, we examine the economics of the construction of new nuclear plant. The two are related since nuclear power can benefit from carbon credits under a system of joint implementation and carbon trading, as noted by Pearce et al. [28]. 


\subsection{Social Cost of Carbon}

The social cost of carbon is an estimate of the present monetary value of damage done by anthropogenic carbon-dioxide emissions. It is generally estimated using an integrated assessment model, ${ }^{13}$ which combines a simplified climate science model with an economic model. The social cost of carbon, essentially a shadow price of carbon emissions, is highly relevant to climate change policy. The UK government uses a semi-official value of $£ 70 / \mathrm{tC}$ [4], although the validity of the number is disputed [29] and is still under review.

Obviously, investment in climate change mitigation is more attractive when a higher social cost of carbon is employed. The discounting framework employed has a significant impact upon such estimates - a lower (constant) discount rate will selfevidently increase the present value of the marginal damage from emissions. It is also clear that use of a declining, rather than a constant, discount rate can materially impact the estimate $[11,13,23]$.

An important question is whether there is much difference between discounting schemes for different countries. To answer this question, we apply the outcomes of our discounting models to the base case damage profile of FUND 2.8 to produce different estimates of the social cost of carbon. ${ }^{14}$ These are presented in Table

\footnotetext{
${ }^{13} \mathrm{Tol}[34]$ provides a meta-analysis of estimates. Examples of integrated assessment models include the Policy Analysis of the Greenhouse Effect (PAGE2002) as employed by Hope [15, 16], the Climate Framework for Uncertainty, Negotiation and Distribution (FUND 2.8) outlined in Tol $[32,33]$, and the Regional Dynamic Integrated model of Climate and the Economy (RICE-99), as explained by Nordhaus and Boyer [24].

${ }^{14}$ Note that this is only intended to illustrate cross-country differences in discounting schemes, rather than produce to any robust conclusions about the social cost of carbon. Correctly estimating
} 
10, which clearly reveals that the specific model matters a great deal, as does the particular country. The regime-switching model implies higher estimates of the social cost of carbon across all four countries than the autoregressive model. The results from the autoregressive model are not substantially different from a constant $3.5 \%$ discount rate, except in the case of Canada, while the regime-switching model increases the social cost of carbon from 31\% (Germany) to 150\% (Canada) compared with the constant discount rate. Of course, more than doubling the social cost of carbon would have formidable implications for climate and energy policy.

\subsection{Nuclear Power}

Construction of new nuclear power stations is increasingly being considered in the United Kingdom - as elsewhere in the world — for its benefits in providing security of energy supply and meeting long run climate change targets. Although previously viewed as an 'unattractive option', the latest Energy Review conducted by the United Kingdom Department of Trade and Industry [5] concluded that 'nuclear has a role to play in the future UK generating mix' because 'the economic of nuclear now look more positive'. It is argued that carbon emission credits may now give nuclear power a cost advantage over coal and gas under reasonable assumptions of reductions in capital costs, operation and maintenance costs, and construction time [2].

To investigate the impact of the different declining discount rate schemes on the

the social cost of carbon requires employing a specific certainty-equivalent discount function for each particular world region (if not each nation) because each region will have a different expected growth path. 
economics of nuclear new build, we make the following assumptions. We assume that a reactor would not be operational for seven years, would have an operating life of 40 years, followed by decommissioning and then waste management over the following 70 years. Based on estimates by Oxera [25] and Ansolabehere et al. [2], baseline construction costs of the first nuclear plant are estimated at $£ 1,600 / \mathrm{kW}$, and then allowing for first-of-a-kind, public enquiry costs, and 10\% for over-run costs, this is increased to $£ 2,000 / \mathrm{kW} .{ }^{15}$ Further assumptions include a capacity factor of $85 \%$, fuel cost of $0.3 \mathrm{p} / \mathrm{kWh}$, operating and maintenance cost of $0.35 \mathrm{p} / \mathrm{kWh}$, and revenues based upon a price of $2.5 \mathrm{p} / \mathrm{kWh}$.

The UK Performance and Innovation Unit [30] concluded that 'it is impossible to estimate waste management costs in any useful way at present' due to the immense uncertainty. But obviously some estimate is needed for a cost-benefit analysis, so for illustration purposes we assume combined decommissioning and waste management costs of $£ 20 / \mathrm{kW}$ per year over the 70 year period. Using a constant $3.5 \%$ discount rate, this is equivalent to a fund of $£ 500 / \mathrm{kW}$ at the beginning of the waste management period, consistent with the estimates in Oxera [25]. Finally, the implicit carbon credit from nuclear generation is calculated using the social cost of carbon from the previous section, coupled with the assumption that nuclear power displaces gas-generated electricity with carbon intensity of $117.8 \mathrm{gC} / \mathrm{kWh}[27]$.

The results of the analysis are presented in Table 11, which reveals three separate impacts of shifting to declining discount rates. First, the present value of waste

\footnotetext{
${ }^{15}$ All estimates are in 2005 money. The capital cost estimates are quite conservative - a fixedprice of $£ 1140 / \mathrm{kW}$ has been agreed for a new nuclear reactor in Finland, and the Performance and Innovation Unit [30] note that capital expenditure may decrease quite substantially in the long-run, especially if a programme of several nuclear reactors was agreed.
} 
and decommissioning costs increases. Second, the implicit carbon credit increases. Third, the net present value of revenues is increased, however this effect will similarly benefit other long-lived electricity generation technologies, whether carbon-intensive or not. As such, the key question is whether the increase in the implicit carbon credit dominates the present value of waste and decommissioning costs. On the assumptions employed here, the carbon credit effect dominates, so that moving to declining discount rates — especially based on a regime-switching model — improves the economics of nuclear power.

While the direction of these results are consistent between models, there are quantitative differences between the autoregressive and the regime-switching schemes. The impact of the autoregressive model on nuclear economics is modest, except in the Canadian case. There are also important differences between countries. For Canada, both the autoregressive and the regime-switching scheme substantially increase the present value of waste and decommission costs and the implicit carbon credit. In contrast, in Germany and the UK the impact of both the autoregressive and the regime-switching models appears to be more modest. Australia shows a dramatic difference between the two models. Overall, the clear message is that the inter-model and inter-country differences are important.

\section{Conclusions}

The analysis in this paper leads to two important conclusions on the appropriate social discount rate for long-term projects, policies and programs. First, model selection is extremely important in developing a schedule of certainty-equivalent 
discount rates for long-term policy appraisal and evaluation. We found that the simple autoregressive model used by Newell and Pizer [23] is inferior to a regimeswitching model of past interest rate behavior, for all four countries examined. This is not a trivial finding - our case studies demonstrate that the policy differences between the autoregressive and regime-switching models can be substantial. In all countries examined, the regime-switching model places a substantially higher weight on events in the distant future. This generates higher estimates of the social cost of carbon, and also improves the economics of nuclear build.

Second, country heterogeneity is also important in formulating social discount rates. A clear conclusion is that even between the four developed economies examined here - Australia, Canada, Germany and the United Kingdom - there are substantial differences in the appropriate schedule of discount rates. ${ }^{16}$ Simply transferring a discounting schedule developed in one jurisdiction to another would clearly be unwise. For instance, the Canadian certainty-equivalent discount rate declines more rapidly than for the other countries, reflecting higher uncertainty in past Canadian interest rates. A corresponding finding is that the net present value of (global) marginal carbon damages under the Canadian scheme is approximately double that under the German scheme.

Finally, we should emphasize that the analysis here is based on two important assumptions, following Newell and Pizer [23]. First, it is assumed that the uncertainty in the real risk-free interest rate provides a rough approximation of the uncertainty in the social discount rate. In theory, it would be preferable to directly estimate

\footnotetext{
${ }^{16}$ This includes differences in the mean discount rate - the initial certainty-equivalent discount rate - as well as differences in the rate of decline of the certainty-equivalent discount rate. We have focussed on the second effect in the this paper.
} 
the certainty-equivalent social rate of time preference. In practice, however, it is difficult to obtain a reliable (and sufficiently long) time series of appropriate utility discount rates and the marginal elasticities of utility.

Second, it is assumed that past uncertainty provides at least some guide to future uncertainty. This seems to us to be a reasonable starting point. The alternative viewpoint — that the past provides relatively little guidance to the future — implies that policy makers should develop a range of future scenarios, each with an associated economic growth rate and corresponding discount rate, and then assign subjective probabilities to these alternative scenarios. This permits the calculation of the appropriate certainty-equivalent discount rate for social cost benefit analysis. Whether an econometric or a scenario approach is employed, the certainty-equivalent discount rates will almost certainly decline through time. Moreover, the two central conclusions of this paper will still apply: careful analysis of the particular model (or set of scenarios) is necessary, and country heterogeneity is likely to be significant. 


\section{References}

[1] A. Ang, G. Bekaert, Regime switches in interest rates, Journal of Business and Economic Statistics 20 (2002) 163-182.

[2] S. Ansolabehere, J. Deutch, M. Driscoll, P. Gray, J. Holdren, P. Joskow, R. Lester, E. Moniz, N. Todreas, The Future of Nuclear Power, An Interdisciplinary MIT Study, Massachusetts Institute of Technology (2003).

[3] G. Chichilnisky, What is sustainable development?, Land Economics 73 (1997) 467-491.

[4] R. Clarkson, K. Deyes, Estimating the social cost of carbon emission, Government Economic Service Working Paper 140 .

[5] Department of Trade and Industry, The Energy Challenge: Energy Review Report 2006, London: HM Government (2006).

[6] D. A. Dickey, W. A. Fuller, Distribution of the estimators for autoregressive time series with a unit root, Journal of the American Statistical Association 74 (1979) 427-431.

[7] S. Frederick, G. Loewenstein, T. O’Donoghue, Time preference and time discounting: A critical review, Journal of Economic Literature XL (2002) 351-401.

[8] C. Gollier, Discounting an uncertain future, Journal of Public Economics 85 (2002) 149-166.

[9] C. Gollier, Time horizon and the discount rate, Journal of Economic Theory 107 (2002) 463-473. 
[10] C. Gollier, R. Zeckhauser, Aggregation of heterogeneous time preferences, Journal of Political Economy 113 (2005) 878-896.

[11] B. Groom, C. Hepburn, P. Koundouri, D. Pearce, Discounting the future: the long and the short of it, Environmental and Resource Economics 31 (2005) $445-493$.

[12] B. Groom, P. Koundouri, E. Panopoulou, T. Pantelidis, Discounting the distant future: How much does model selection affect the certainty equivalent rate?, Journal of Applied Econometrics . (2006) forthcoming.

[13] J. Guo, C. Hepburn, R. S. J. Tol, D. Anthoff, Discounting and the social cost of carbon: A closer look at uncertainty, Environmental Science and Policy 9 (2005) 205-216.

[14] HM Treasury, The Green Book: Appraisal and Evaluation in Central Government, London: HM Treasury (2003).

[15] C. Hope, Integrated assessment models, in: D. Helm (Ed.), Climate-change policy, Oxford, UK: Oxford University Press (2005), 77-98.

[16] C. Hope, The marginal impact of $\mathrm{CO}_{2}$ from PAGE2002: An integrated assessment model incorporating the ipccs five reasons for concern, Integrated Assessment Journal 6 (2006) 19-56.

[17] R. J. Kopp, P. R. Portney, Mock referenda for intergenerational discounting, in: P. R. Portney, J. P. Weyant (Eds.), Discounting and intergenerational equity, Washington, DC: Resources for the Future (1999), 87-98.

[18] D. Kwiatkowski, P. C. B. Phillips, P. Schmidt, Y. Shin, Testing the null hypothesis of stationarity against the alternative of a unit root: How sure are we 
that economic time series have a unit root?, Journal of Econometrics 54 (1992) $159-178$.

[19] C.-Z. Li, K.-G. Löfgren, Renewable resources and economic sustainability: a dynamic analysis with heterogeneous time preferences, Journal of Environmental Economics and Management 40 (2000) 236-250.

[20] C.-Z. Li, K.-G. Löfgren, Economic growth, environmental quality and hyperbolic discounting, mimeo .

[21] R. C. Lind, A primer on the major issues relating to the discount rate for evaluating national energy options, in: R. C. Lind (Ed.), Discounting for Time and Risk in Energy Policy, Washington, DC: Resources for the Future (1982), $21-94$.

[22] G. Loewenstein, D. Prelec, Anomalies in intertemporal choice: Evidence and an interpretation, Quarterly Journal of Economics 107 (1992) 573-597.

[23] R. Newell, W. A. Pizer, Discounting the distant future: How much do uncertain rates increase valuations?, Journal of Environmental Economics and Management 56 (2003) 52-71.

[24] W. D. Nordhaus, J. Boyer, Warming the world: Economic Models of Global Warming, MIT Press, Cambridge, MA (2000).

[25] Oxera, Financing the nuclear option, Agenda June (2005) 1-5, see: www.oxera.com/main.aspx?id=3566.

[26] T. Page, Balancing efficiency and equity in long-run decision-making, International Journal of Sustainable Development 6 (2003) 70-86. 
[27] J. Peña Torres, P. J. G. Pearson, Carbon abatement and new investment in liberalised electricity markets: A nuclear revival in the UK?, Energy Policy 28 (2000) 115-135.

[28] D. Pearce, B. Groom, C. Hepburn, P. Koundouri, Valuing the future: Recent advances in social discounting, World Economics 4 (2003) 121-141.

[29] D. W. Pearce, The social cost of carbon and its policy implications, Oxford Review of Economic Policy 19 (2003) 362-384.

[30] Performance and Innovation Unit, The energy review, London: Performance and Innovation Unit (2002).

[31] T. Schelling, Intergenerational discounting, Energy Policy 23 (1995) 395-401.

[32] R. S. J. Tol, Estimates of the damage costs of climate change, part ii: Dynamic estimates, Environmental and Resource Economics 21 (2002) 135-160.

[33] R. S. J. Tol, New estimates of the damage costs of climate change, part i: benchmark estimates, Environmental and Resource Economics 21 (2002) 4773.

[34] R. S. J. Tol, The marginal damage costs of carbon dioxide emissions: an assessment of the uncertainties, Energy Policy 33 (2005) 2064-2074.

[35] M. L. Weitzman, Why the far-distant future should be discounted at its lowest possible rate, Journal of Environmental Economics and Management 36 (1998) 201-208.

[36] M. L. Weitzman, Gamma discounting, American Economic Review 91 (2001) 261-271. 
[37] M. L. Weitzman, Discounting a distant future whose technology is unknown, mimeo . 
Table 1: Descriptive Statistics and Unit Root Tests

\begin{tabular}{lcccc}
\hline \hline Country & Australia & Canada & Germany & UK \\
\hline Mean & 1.219 & 1.084 & 1.310 & 1.206 \\
St.dev & 0.387 & 0.786 & 0.412 & 0.506 \\
Skewness & -1.227 & -1.527 & -2.125 & -0.979 \\
Kurtosis & 5.314 & 5.984 & 9.524 & 4.810 \\
Min & -0.236 & -2.344 & -0.714 & -0.882 \\
Max & 1.909 & 2.502 & 1.980 & 2.035 \\
ADF & $-3.248^{*}$ & $-4.149^{* *}$ & $-3.734^{* *}$ & $-3.189^{* *}$ \\
KPSS & 0.122 & 0.234 & 0.219 & 0.042 \\
Sample & $1866-2004$ & $1854-2004$ & $1814-2004$ & $1812-2004$ \\
\hline \hline
\end{tabular}

Notes: All variables are in logs. ADF: Augmented Dickey-Fuller test [6]. KPSS test: see Kwiatkowski et al. [18]. (**) indicates the rejection of the null hypothesis at $1 \%$ level; $(*)$ indicates the rejection of the null hypothesis at $5 \%$ level.

Table 2: Estimation Results (AR(p) models)

\begin{tabular}{lcccc}
\hline \hline Country & Australia & Canada & Germany & UK \\
\hline \multirow{2}{*}{$n$} & 1.187 & 1.065 & 1.260 & 1.201 \\
& $(0.107)$ & $(0.189)$ & $(0.126)$ & $(0.177)$ \\
$a_{1}$ & 1.311 & 0.789 & 1.784 & 1.054 \\
& $(0.084)$ & $(0.051)$ & $(0.068)$ & $(0.058)$ \\
$a_{2}$ & -0.331 & & -1.246 & -0.125 \\
& $(0.133)$ & - & $(0.117)$ & $(0.089)$ \\
$a_{3}$ & -0.416 & & 0.399 & -0.443 \\
& $(0.132)$ & - & $(0.068)$ & $(0.070)$ \\
$a_{4}$ & 0.560 & & & 0.368 \\
& $(0.135)$ & - & - & $(0.035)$ \\
$a_{5}$ & -0.235 & - & - & - \\
& $(0.085)$ & & & 0.064 \\
$\sigma_{\xi}^{2}$ & 0.019 & 0.023 & 0.011 & $(0.005)$ \\
\hline \hline
\end{tabular}

Notes: Estimated standard errors are reported in the parentheses. 
Table 3: Estimation Results (Regime Switching Models)

\begin{tabular}{|c|c|c|c|c|}
\hline Country & Australia & Canada & Germany & 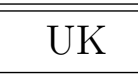 \\
\hline \multirow{2}{*}{$n_{1}$} & 1.304 & 1.041 & 1.353 & 1.306 \\
\hline & $(0.067)$ & $(0.068)$ & $(0.043)$ & $(0.082)$ \\
\hline \multirow{2}{*}{$a_{1}^{1}$} & 1.956 & 0.948 & 1.656 & 1.397 \\
\hline & $(0.044)$ & $(0.010)$ & $(0.113)$ & $(0.079)$ \\
\hline \multirow{2}{*}{$a_{2}^{1}$} & -1.327 & - & -0.775 & -0.530 \\
\hline & $(0.054)$ & - & $(0.181)$ & $(0.058)$ \\
\hline \multirow{2}{*}{$a_{3}^{1}$} & 0.778 & - & 0.075 & - \\
\hline & $(0.047)$ & - & $(0.087)$ & - \\
\hline \multirow{2}{*}{$a_{4}^{1}$} & -0.761 & - & - & - \\
\hline & $(0.051)$ & & & - \\
\hline$a_{5}^{1}$ & $\begin{array}{c}0.306 \\
(0.030)\end{array}$ & - & - & - \\
\hline \multirow[b]{2}{*}{$n_{2}$} & 0.907 & 0.948 & 1.173 & 0.760 \\
\hline & $(0.179)$ & $(0.390)$ & $(0.303)$ & $(0.244)$ \\
\hline \multirow{2}{*}{$a_{1}^{2}$} & 0.878 & 0.771 & 1.781 & 0.700 \\
\hline & $(0.057)$ & $(0.067)$ & $(0.092)$ & $(0.312)$ \\
\hline \multirow{2}{*}{$a_{2}^{2}$} & - & - & -1.247 & -0.212 \\
\hline & - & - & $(0.152)$ & $(0.312)$ \\
\hline$a_{3}^{2}$ & - & - & $\begin{array}{c}0.400 \\
(0.102)\end{array}$ & - \\
\hline \multirow{2}{*}{$\sigma_{1}^{2}$} & $4.7 e-4$ & $2.7 e-4$ & $2.7 e-4$ & 0.014 \\
\hline & $(1.0 e-4)$ & $(5.8 e-5)$ & $(3.6 e-5)$ & $(0.002)$ \\
\hline \multirow{2}{*}{$\sigma_{2}^{2}$} & 0.036 & 0.353 & 0.021 & 0.219 \\
\hline & $(0.006)$ & $(0.038)$ & $(0.003)$ & $(0.047)$ \\
\hline \multirow{2}{*}{$P$} & 0.892 & 0.931 & 0.978 & 0.933 \\
\hline & $(0.049)$ & $(0.043)$ & $(0.015)$ & $(0.033)$ \\
\hline \multirow{2}{*}{$Q$} & 0.927 & 0.973 & 0.988 & 0.767 \\
\hline & $(0.032)$ & $(0.019)$ & $(0.010)$ & $(0.101)$ \\
\hline
\end{tabular}

Notes: Estimated standard errors are reported in the parentheses. 
Table 4: Tests for Regimes

\begin{tabular}{lcccc}
\hline \hline \multicolumn{5}{c}{ Panel A: RCM Test } \\
\hline \hline Country & Australia & Canada & Germany & UK \\
RCM & 48.21 & 22.14 & 16.84 & 49.25 \\
\hline \hline \multicolumn{5}{c}{ Panel B: LR Test } \\
\hline \hline Country & Australia & Canada & Germany & UK \\
Logl AR & 80.67 & -100.67 & 157.48 & -8.94 \\
Logl RS & 135.63 & 27.02 & 286.01 & 43.64 \\
LR & 109.92 & 255.38 & 257.06 & 105.16 \\
p-value* & 0.041 & 0.006 & 0.029 & 0.033 \\
\hline \hline
\end{tabular}

* Based on the simulated distribution of the LR test.

Table 5: Mean Square Forecast Errors

\begin{tabular}{ccccc}
\hline \hline Country & Australia & Canada & Germany & UK \\
AR & 0.1845 & 0.8347 & 0.2948 & 0.3411 \\
RS & 0.1816 & 0.8187 & 0.2904 & 0.3140 \\
\% Difference & 1.60 & 1.95 & 1.51 & 8.63 \\
\hline \hline
\end{tabular}

Table 6: Certainty-Equivalent Discount Factors

\begin{tabular}{lrrrr}
\hline \hline \multicolumn{5}{c}{ AR $(\mathrm{p})$ models } \\
\hline \hline Country & Australia & Canada & Germany & UK \\
\hline \hline 1 & 0.96618 & 0.96618 & 0.96618 & 0.96618 \\
20 & 0.50262 & 0.53091 & 0.50710 & 0.50258 \\
40 & 0.25407 & 0.29535 & 0.25056 & 0.25260 \\
60 & 0.12913 & 0.16617 & 0.12366 & 0.12696 \\
80 & 0.06598 & 0.09455 & 0.06152 & 0.06404 \\
100 & 0.03391 & 0.05431 & 0.03087 & 0.03259 \\
150 & 0.00659 & 0.01418 & 0.00576 & 0.00623 \\
200 & 0.00134 & 0.00392 & 0.00116 & 0.00128 \\
250 & 0.00029 & 0.00114 & 0.00027 & 0.00030 \\
300 & 0.00007 & 0.00034 & 0.00009 & 0.00008 \\
350 & 0.00002 & 0.00011 & 0.00004 & 0.00003 \\
400 & 0.00001 & 0.00004 & 0.00002 & 0.00002 \\
\hline \hline
\end{tabular}


Table 7: Certainty-Equivalent Discount Rates

\begin{tabular}{lcccc}
\hline \hline \multicolumn{5}{c}{ AR(p) models } \\
\hline \hline Country & Australia & Canada & Germany & UK \\
\hline \hline 1 & 3.50 & 3.50 & 3.50 & 3.50 \\
20 & 3.49 & 3.00 & 3.53 & 3.52 \\
40 & 3.45 & 2.95 & 3.61 & 3.54 \\
60 & 3.44 & 2.89 & 3.58 & 3.50 \\
80 & 3.40 & 2.84 & 3.53 & 3.46 \\
100 & 3.38 & 2.79 & 3.50 & 3.42 \\
150 & 3.29 & 2.66 & 3.34 & 3.30 \\
200 & 3.20 & 2.56 & 3.14 & 3.10 \\
250 & 3.01 & 2.46 & 2.68 & 2.77 \\
300 & 2.87 & 2.37 & 1.98 & 2.42 \\
350 & 2.00 & 2.27 & 1.37 & 1.75 \\
400 & 1.03 & 2.16 & 1.02 & 0.99 \\
\hline \hline
\end{tabular}

Table 8: Certainty-Equivalent Discount Factors

\begin{tabular}{lrrrr}
\hline \hline \multicolumn{5}{c}{ Regime Switching Models } \\
\hline \hline Country & Australia & Canada & Germany & UK \\
\hline \hline 1 & 0.96618 & 0.96618 & 0.96618 & 0.96618 \\
20 & 0.54583 & 0.52604 & 0.50443 & 0.51168 \\
40 & 0.30337 & 0.28910 & 0.25650 & 0.26593 \\
60 & 0.16922 & 0.16276 & 0.13181 & 0.13897 \\
80 & 0.09496 & 0.09369 & 0.06872 & 0.07313 \\
100 & 0.05366 & 0.05494 & 0.03634 & 0.03870 \\
150 & 0.01326 & 0.01564 & 0.00791 & 0.00810 \\
200 & 0.00344 & 0.00491 & 0.00195 & 0.00178 \\
250 & 0.00095 & 0.00168 & 0.00056 & 0.00041 \\
300 & 0.00029 & 0.00062 & 0.00020 & 0.00010 \\
350 & 0.00010 & 0.00025 & 0.00009 & 0.00003 \\
400 & 0.00004 & 0.00011 & 0.00005 & 0.00001 \\
\hline \hline
\end{tabular}


Table 9: Certainty-Equivalent Discount Rates

\begin{tabular}{lcccc}
\hline \hline \multicolumn{5}{c}{ Regime Switching models } \\
\hline \hline Country & Australia & Canada & Germany & UK \\
\hline \hline 1 & 3.50 & 3.50 & 3.50 & 3.50 \\
20 & 2.98 & 3.13 & 3.46 & 3.34 \\
40 & 2.98 & 2.99 & 3.41 & 3.31 \\
60 & 2.95 & 2.84 & 3.35 & 3.29 \\
80 & 2.91 & 2.75 & 3.28 & 3.25 \\
100 & 2.88 & 2.67 & 3.20 & 3.22 \\
150 & 2.79 & 2.45 & 2.99 & 3.13 \\
200 & 2.68 & 2.26 & 2.68 & 3.03 \\
250 & 2.52 & 2.07 & 2.31 & 2.91 \\
300 & 2.28 & 1.93 & 1.84 & 2.97 \\
350 & 1.91 & 1.79 & 1.22 & 2.59 \\
400 & 1.46 & 1.61 & 1.05 & 2.22 \\
\hline \hline
\end{tabular}

Table 10: Value of Carbon Damages

\begin{tabular}{lcccc}
\hline \hline & \multicolumn{4}{c}{ Carbon Values $(2005 £ /$ tC) } \\
Model & Australia & Canada & Germany & UK \\
\hline \hline Constant 3.5\% & 6.8 & 6.8 & 6.8 & 6.8 \\
AR(p) & 7.7 & 16.2 & 6.5 & 7.2 \\
Regime Switch & 15.5 & 17.3 & 8.9 & 9.5 \\
\hline \hline & Relative to constant rate $(3.5 \%)$ \\
AR(p) & $12 \%$ & $140 \%$ & $-4.1 \%$ & $5.7 \%$ \\
Regime Switch & $130 \%$ & $150 \%$ & $31 \%$ & $39 \%$ \\
\hline \hline
\end{tabular}


Table 11: The Costs and Benefits of Nuclear Build in the UK*

\begin{tabular}{lccccc}
\hline \hline$(2005 £ / \mathrm{kW})$ & Revenue & Costs & Waste/Decomm & Carbon Credit & NPV \\
\hline \hline Australia & & & & & \\
Constant 3.5\% & 3230 & -2840 & -110 & 240 & 530 \\
AR(p) & 3240 & -2840 & -110 & 270 & 560 \\
Regime Switch & 3551 & -2923 & -150 & 546 & 1030 \\
\hline Canada & & & & & \\
Constant 3.5\% & 3230 & -2840 & -110 & 240 & 530 \\
AR(p) & 3470 & -2900 & -150 & 570 & 990 \\
Regime Switch & 3430 & -2890 & -150 & 610 & 1000 \\
\hline Germany & & & & & \\
Constant 3.5\% & 3230 & -2840 & -110 & 240 & 530 \\
AR(p) & 3250 & -2840 & -100 & 230 & 530 \\
Regime Switch & 3250 & -2850 & -110 & 310 & 610 \\
\hline United Kingdom & & & & & \\
Constant 3.5\% & 3230 & -2840 & -110 & 240 & 530 \\
AR(p) & 3230 & -2840 & -110 & 250 & 540 \\
Regime Switch & 3310 & -2860 & -120 & 330 & 660 \\
\hline *Totals may not add due to rounding
\end{tabular}

*Totals may not add due to rounding. 